\title{
Phase I trial of bortezomib and dacarbazine in melanoma and soft tissue sarcoma
}

\author{
Andrew Poklepovic, \\ Massey Cancer Center and the Division of Hematology, Oncology \& Palliative Care, Virginia \\ Commonwealth University, Richmond, VA 23298-0037, USA
}

Leena Youseffian,

School of Medicine, Virginia Commonwealth University, Richmond, VA 23298-0037, USA

Mary Winning,

Massey Cancer Center, Virginia Commonwealth University, Richmond, VA 23298-0037, USA

Christine A. Birdsell,

Massey Cancer Center, Virginia Commonwealth University, Richmond, VA 23298-0037, USA

Nancy A. Crosby,

Norris Cotton Cancer, Geisel School of Medicine, Dartmouth Hitchcock Medical Center, Lebanon, $\mathrm{NH}$ 03756, USA

\section{Viswanathan Ramakrishnan, \\ Massey Cancer Center, Virginia Commonwealth University, Richmond, VA 23298-0037, USA}

Marc S. Ernstoff, and

Norris Cotton Cancer, Geisel School of Medicine, Dartmouth Hitchcock Medical Center, Lebanon, $\mathrm{NH}$ 03756, USA

\author{
John D. Roberts \\ Massey Cancer Center and the Division of Hematology, Oncology \& Palliative Care, Virginia \\ Commonwealth University, Richmond, VA 23298-0037, USA
}

\section{Summary}

Purpose-Preclinical studies in human melanoma cell lines and murine xenograft tumor models suggest that the proteasome inhibitor bortezomib enhances the activity of the cytotoxic agent dacarbazine. We performed a phase I trial of bortezomib and dacarbazine in melanoma, soft tissue sarcoma, and amine precursor uptake and decarboxylation tumors. The primary objective was to identify recommended phase II doses for the combination.

Experimental design-Bortezomib and dacarbazine were both administered intravenously once weekly. All patients received prophylactic antiemetics. Dose escalation proceeded using a standard 3+3 design. Response was assessed according to NCI RECIST v1.0.

Results-Twenty eight patients were enrolled to six dose levels. Bortezomib $1.6 \mathrm{mg} / \mathrm{m}^{2}$ and dacarbazine $580 \mathrm{mg} / \mathrm{m}^{2}$ are the recommended phase II weekly doses. The combination was generally well tolerated. Among 15 patients with melanoma there was one durable complete response in a patient with an exon-11 cKIT mutation, and one partial response. Among 12 patients with soft tissue sarcoma there was one partial response.

(C) Springer Science+Business Media New York 2013

J. D. Roberts john.d.roberts@yale.edu.

Conflict of interest disclosures The authors have no relevant conflicts to report. 
Conclusions-Bortezomib $1.6 \mathrm{mg} / \mathrm{m}^{2}$ and dacarbazine $580 \mathrm{mg} / \mathrm{m}^{2}$ administered intravenously once weekly is well tolerated and has at least minimal activity in melanoma and soft tissue sarcoma.

\section{Keywords}

Bortezomib; Dacarbazine; Melanoma; Soft tissue sarcoma; Phase I trial

\section{Introduction}

Dacarbazine and temozolomide, which are both used in the treatment of a variety of malignancies including melanoma and sarcoma, are prodrugs for the cytotoxic alkylating moiety monomethyl triazineimidazole carboxamide [1]. Nuclear factor-kappa B (NF-kappa B) is an inducible transcription factor that regulates the expression of many genes including genes related to apoptosis [2]. NF-kappa B activity frequently is upregulated in melanoma as well as many other cancers, and this may be a source resistance to alkylating agents [2]. In preclinical studies bortezomib, the prototype proteasome inhibitor, frequently downregulates NF-kappa B [3,4]. Preclinical studies in human melanoma cell lines and murine xenograft melanoma tumor models suggest that addition of bortezomib to dacarbazine or temozolomide enhances their activity against melanoma [3, 4]. This creates a rationale for combining bortezomib with one of these agents in the clinic.

The initial FDA approved dose of bortezomib was $1.3 \mathrm{mg} / \mathrm{m}^{2}$ administered twice weekly for 2 weeks and repeated every 3 weeks [5]. In the treatment of melanoma dacarbazine commonly is administered as a single intravenous (iv) infusion of $850-1,000 \mathrm{mg} / \mathrm{m} 2$ every 3 weeks $[6,7]$. We considered that maximum antitumor activity of the combination might be accomplished with an administration schedule that facilitated interaction between the two agents. Bortezomib inhibition of proteasome activity is apparent within minutes and persists for hours or days as measured in peripheral blood mononuclear cells [8]. Following metabolic activation dacarbazine's active moiety induces mono-functional alkyl-DNA adducts that have a half-time of about 3 days as measured in peripheral blood mononuclear cells [9]. These pharmacodynamic profiles suggested that concurrent weekly administration might be an effective strategy. Although even greater dose intensity might have been achievable with twice weekly administration, we considered this to be unacceptably inconvenient for a presumed palliative therapy. We specified administration in the sequence bortezomib followed by dacarbazine in order that the consequences of bortezomib induced proteasome inhibition might be unfolding as dacarbazine metabolites appeared in the circulation.

We did not choose a schedule involving arbitrarily chosen weeks without drug administration (for example, no drug every third week), such as is standard for bortezomib and many other agents and combinations, on the presumption that optimal timing of treatment omission in order to maintain maximum dose intensity varies from patient to patient.

The common, serious toxicities of bortezomib are myelosuppresssion and peripheral neuropathy [10]. We thought it would be of interest to learn whether weekly administration is associated with less neuropathy. During dacarbazine development the dose limiting toxicity (DLT) was nausea and vomiting [11]. The advent of more effective antiemetics has rendered this toxicity manageable, and currently dose limiting toxicities probably are myelosuppression, especially leucopenia and thrombocytopenia, and maximum tolerated doses have not been defined. As both drugs cause myelosuppression, we suspected that this would be the dose limiting toxicity. We elected to begin with a low dacarbazine dose of 250 
$\mathrm{mg} / \mathrm{m}^{2}$, which over 3 weeks is slightly less dose intense than the usual schedule, and to escalate (if tolerated) to a high dose of $580 \mathrm{mg} / \mathrm{m}^{2}$, which represents a nearly two fold increase in dose intensity as compared with the usual schedule. We elected to start with the standard dose of bortezomib of $1.3 \mathrm{mg} / \mathrm{m}^{2}$ and to escalate only to the highest recommended dose of $1.6 \mathrm{mg} / \mathrm{m}^{2}[12]$.

Although preclinical studies supporting the combination were done in melanoma cell lines, we planned to include patients with soft tissue sarcomas and, subsequently, amine precursor uptake and decarboxylation (APUD) tumors, in order to expedite completion of the study. We considered this to be reasonable as the presumed mechanism of interaction might be relevant to these dacarbazine sensitive tumors $[13,14]$.

\section{Patients and methods \\ Centers and patients}

Patients were treated at two centers. Eligibility requirements included: age 18 years or older; histologic diagnosis of cutaneous or mucosal melanoma, soft tissue sarcoma, or APUD tumor; not appropriate for surgery and/or radiation treatment with curative intent; measurable or evaluable disease; and an ECOG performance status of 0 or 1 . Ineligibility criteria included: uncontrolled brain metastasis; platelets $<100,000$ cells $/ \mathrm{mm}^{3}$; neutrophils $<1,500$ cells $/ \mathrm{mm}^{3}$; hemoglobin $<10 \mathrm{gm} / \mathrm{dL}$; calculated creatinine clearance $<30 \mathrm{~mL} /$ minute using the Cockcroft and Gault formula; and peripheral neuropathy grade $\geq 2$ (see below). There was no limit on number of prior therapies. The study was conducted according to an institutional review board approved protocol. All patients gave written informed consent. The study was registered at http://clinicaltrials.gov with identifier NCT00580320.

\section{Administration and dose escalation}

Patients received bortezomib and dacarbazine on the same day once weekly with at least 5 days elapsed between each treatment. Bortezomib (supplied as Velcade ${ }^{\mathrm{TM}}$ by Millenium Pharmaceutics, Inc.) was administered as an iv push over 3 to $5 \mathrm{~s}$ followed by dacarbazine by iv infusion. Six dose levels were tested (Table 1).

\section{Dose limiting toxicity (DLT), dose escalation, maximum tolerated dose (MTD), recommended phase II doses (RP2D), and statistical methods}

DLT was defined as any grade 3 non-hematologic or grade 4 hematologic toxicity except lymphopenia that occurred within the first 6 weeks of treatment. Patients who discontinued treatment prior to 6 weeks for reasons other than DLT were scored as not evaluable for DLT. All adverse events were noted and categorized according to the NCI Common Terminology Criteria for Adverse Events version 3.0. Adverse events categorized as definitely, probably, or possibly related to study treatment were scored as toxicities.

Patients were enrolled in cohorts of 3. For any dose level, if DLT was experienced in 0 of 3 or $0 / 1$ of 6 patients evaluable for DLT, the next cohort was enrolled at the next dose level (Table 1). For any dose level, if two of up to six patients experienced DLT, dose escalation was stopped and the next lowest dose was declared the MTD, subject to the condition that declaration of an MTD required treatment of six evaluable patients. The RP2D was to be the MTD unless the pattern of dose omissions and toxicities throughout the course of treatment suggested that lower doses might be preferred. Results are described with descriptive statistics. 


\section{Dose modification}

Dose escalation above a patient's enrollment dose was not permitted. Doses were modified according to the type and grade of toxicity. Grade 3 or 4 hematologic toxicity required dose omission until resolution to grade 2 or less and then dose de-escalation. Leucocyte growth factors were not permitted during the first 6 weeks of treatment except in patient's experiencing febrile neutropenia. Transient grade 2 non-hematologic toxicity was managed at the investigator's discretion. Persistent grade 2 non-hematologic toxicity required dose de-escalation. Grade 3 or 4 non-hematologic toxicity required dose omission until resolution to grade 2 or less and then dose de-escalation. Neuropathic pain (NP) and/or peripheral sensory neuropathy (PSN) required dose modification of bortezomib alone according to a schema similar to that described in the prescribing information [11].

Patient assessments. Patients had weekly evaluations including interval history, weight, performance status, concurrent medications, complete blood cell count, serum chemistries, and toxicity assessment, Physical exam was performed monthly or more often as indicated. Tumor responses were assessed according to NCI RECIST v1.0 every 2 months while on treatment and as clinically indicated subsequently.

\section{Results}

\section{Patient characteristics}

Twenty eight patients were enrolled at two institutions from 2003 to 2007 (Table 2). Fifteen patients had melanoma, 12 patients had soft tissue sarcoma (STS) including leiomysarcoma [5], fibrosarcoma (2), unclassifiable (2), liposarcoma (1), spindle cell sarcoma (1), and malignant fibrous histiocytoma (1), and one patient had an amine precursor uptake and decarboxylase (APUD) tumor. Most patients had not had prior systemic therapy for metastatic disease.

\section{Toxicities, schedule and dose adherence, and recommended phase II doses}

Treatment was generally well tolerated (Tables 1 and 3). Only one patient, who was treated at dose level 3, experienced a dose limiting toxicity, which was emesis. Two of six patients treated at the highest dose level experienced dose omissions for toxicity within the first 8 weeks of treatment. The timing of dose omissions differed between these two patients. During the entire course of treatment diverse grade 1 and 2 toxicities were common and grade 3 toxicities were frequent; as a result, dose reductions were frequent; for example, among five patients treated at the highest dose level for at least 18 weeks, four experienced dose reductions. Neuropathy was uncommon and mild, not requiring dose modifications. The MTD and RP2D weekly doses are bortezomib $1.6 \mathrm{mg} / \mathrm{m}^{2}$ and dacarbazine $580 \mathrm{mg} / \mathrm{m}^{2}$.

\section{Responses}

Among 15 patients with melanoma there was one CR of $>42$ months duration and one PR of 6 months duration (Table 4). The patient experiencing a CR was initially treated at the highest dose level but experienced four dose reductions for myelosuppression before treatment was discontinued. The CR evolved over the first 20 months of treatment, treatment was discontinued at 28 months, and the CR has persisted for more than 14 months since treatment was discontinued (Figs. 1 and 2). Subsequent molecular testing has revealed that this patient's melanoma harbors an exon-11 $c$-KIT mutation. The patient has sun-damaged skin and has been treated for non-melanoma skin cancers both before and after receiving study treatment, although the incidence appears to have increased. She also developed a culture-confirmed atypical mycobacterial infection of the lungs late in the course of therapy that requires ongoing antibiotic therapy. She has persistent mild cytopenias; whether these are due solely to study treatment or also at least in part due to ongoing antibiotic therapy is 
unknown. She also has noted complete freedom from migraine headaches since starting treatment and continuing since treatment was discontinued that had been persistent for five decades. Among 12 patients with STS there was one PR.

\section{Discussion}

Despite the presence of a second myelosuppressive agent, the RP2D for dacarbazine in the combination represents a nearly two fold increase in dose intensity as compared with the previous recommended dose for single agent administration. This could be the result of improvements in antiemetic therapy and/or subadditive toxicity with weekly administration. The dose intensity hypothesis holds that routine dose intensification through this approach might improve outcomes and perhaps expand indications for this old drug. On the other hand, toxicities ultimately are cumulative so that dose modification is the rule rather than the exception when treatment continues for more than a few months.

At the RP2D four of six patients tolerated weekly administration for eight consecutive weeks. The patterns of dose omissions in the remaining two patients differed. This suggests that the common scheduling strategy of routine, arbitrarily chosen weeks without drug administration may sacrifice dose intensity.

It is remarkable that minimal neuropathy was observed despite weekly treatment at the higher of the two recommended bortezomib doses [9]. This suggests that there is a pharmacodynamic difference between twice weekly and weekly administration that alters the toxicity profile

Although the antitumor activity seen against both melanoma and STS was not greater than what might have occurred with dacarabazine alone, most patients were treated with doses significantly lower than the RP2D, and it remains unknown whether the combination is more active.

We were aware while we were designing and conducting our study that others, motivated by the same preclinical findings, were pursuing the combination of bortezomib and temozolomide in melanoma [15]. We thought that simultaneous pursuit of both projects was reasonable given the promising preclinical results and contemporary paucity of promising therapeutic concepts. Neuropathy was a common toxicity in that study, probably because these investigators used a conventional twice weekly bortezomib administration schedule. They observed one response in 19 patients, a finding that is subject to the same caveats as apply to our study.

In the interval since the design of these studies, two new drugs with striking activity in melanoma have been developed and approved: Vemurafenib, which is targeted to the common $\mathrm{BRAF}^{\mathrm{V} 600 \mathrm{E}}$ mutation, induces $\mathrm{PR}$ in $\sim 50 \%$ of patients and prolongs survival as compared with dacarbazine, although sustained remissions are anecdotal [6]. Ipilimumab, which blocks cytotoxic T-lymphocyte-associated antigen 4 to potentiate an antitumor T-cell response, induces $\mathrm{CR}$ in $\sim 15 \%$ of patients, many of which are delayed in onset, and prolongs survival as compared with a presumed inactive peptide "vaccine" $[7,16]$. Of greater potential significance, up to half of these CR appear to be durable, raising the possibility of cure [17].

Of particular interest in this study is the observation of a durable and ongoing complete remission in the patient with $c$-KIT mutated melanoma. This mutation typically does not overlap with $B R A F$ mutations and is found in distinct subsets of melanoma including mucosal melanoma, acral lentiginous melanoma, and melanoma arising in a background of chronic sun-damaged skin [18]. Gastrointestinal stromal tumor (GIST) is another KIT 
mutation driven cancer. Preclinical data suggest that bortezomib has a dual mode of action against KIT mutant GIST cells involving upregulation of the proapoptotic histone H2AX and downregulation of $K I T$ transcription [19]. Importantly, bortezomib was active in vitro against imatinib-resistant GIST cells in a short-term culture derived from an imatinibresistant GIST in vitro [20]. Clinical studies in KIT mutated melanoma using imatinib were based on molecular pathways and responses seen in GIST, and responses have been moderate thus far [20]. The finding of a durable CR in response to bortezomib based therapy in a melanoma patient with a KIT exon-11 mutation suggests that a future study of dacarbazine and bortezomib might prove worthwhile in this subpopulation of patients with metastatic melanoma.

Activated NF-kappaB continues to be considered a potential barrier to more effective treatment of melanoma, and research continues to target proteasome inhibitor mediated modulation of NF-kappaB as a therapeutic strategy [21]. An unanticipated interval finding regarding bortezomib has been that in certain lung cancer cell lines it appears to up regulate, not down regulate, NF-kappaB [22]. The relevance of this to melanoma is unknown.

Better treatments for melanoma and soft tissue sarcoma remain an important unmet need. Further exploration of novel, rational combinations remains appropriate.

\section{Acknowledgments}

Supported in part by P30CA016059 (NCI), M01RR000065 (NCRR), and a grant from Millennium Pharmaceuticals, Inc.

\section{References}

1. Middleton MR, Grob JJ, Aaronson N, Fierlbeck G, Tilgen W, Seiter S, et al. Randomized phase III study of temozolomide versus dacarbazine in the treatment of patients with advanced metastatic malignant melanoma. J Clin Oncol. 2000; 18:158-166. [PubMed: 10623706]

2. McConkey DJ, Zhu K. Mechanisms of proteasome inhibitor action and resistance in cancer. Drug Resist Updat. 2008; 11:164-179. [PubMed: 18818117]

3. Amiri K, Richmond A. The novel proteasome inhibitor bortezomib (VELCADE), formerly known as PS-341, inhibited growth and overcame drug resistance in human malignant melanoma in vitro and in mice. Proc AACR. 2003; 44:165.

4. Amiri KI, Horton LW, LaFleur BJ, Sosman JA, Richmond A. Augmenting chemosensitivity of malignant melanoma tumors via proteasome inhibition: implication for bortezomib (VELCADE, PS-341) as a therapeutic agent for malignant melanoma. Cancer Res. 2004; 64:4912-4918. [PubMed: 15256463]

5. Kane RC, Farrell AT, Sridhara R, Pazdur R. United States Food and Drug Administration approval summary: bortezomib for the treatment of progressive multiple myeloma after one prior therapy. Clin Cancer Res. 2006; 12:2955-2960. [PubMed: 16707588]

6. Chapman PB, Hauschild A, Robert C, Haanen JB, Ascierto P, Larkin J, Dummer R, Garbe C, Testori A, Maio M, Hogg D, Lorigan P, Lebbe C, Jouary T, Schadendorf D, Ribas A, O'Day SJ, Sosman JA, Kirkwood JM, Eggermont AM, Dreno B, Nolop K, Li J, Nelson B, Hou J, Lee RJ, Flaherty KT, McArthur GA, BRIM-3 Study Group. Improved survival with vemurafenib in melanoma with BRAF V600E mutation. N Engl J Med. 2011; 364:2507-2516. [PubMed: 21639808]

7. Robert C, Thomas L, Bondarenko I, O'Day S, JW MD, Garbe C, Lebbe C, Baurain JF, Testori A, Grob JJ, Davidson N, Richards J, Maio M, Hauschild A, Miller WH Jr, Gascon P, Lotem M, Harmankaya K, Ibrahim R, Francis S, Chen TT, Humphrey R, Hoos A, Wolchok JD. Ipilimumab plus dacarbazine for previously untreated metastatic melanoma. N Engl J Med. 2011; 364:25172526. [PubMed: 21639810]

8. Adams J. The development of proteasome inhibitors as anticancer drugs. Cancer Cell. 2004; 5:417421. [PubMed: 15144949] 
9. Lawley PD, Phillips DH. DNA adducts from chemotherapeutic agents. Mutat. 1996; 355:13-40.

10. Millennium Pharmaceuticals, Inc. VELCADE (bortezomib) for injection prescribing information. 2012

11. Hopsira, Inc. Dacarbazine for injection prescribing information. 2007

12. Aghajanian C, Soignet S, Dizon DS, Pien CS, Adams J, Elliott PJ, Sabbatini P, Miller V, Hensley ML, Pezzulli S, Canales C, Daud A, Spriggs DR. A phase I trial of the novel proteasome inhibitor PS341 in advanced solid tumor malignancies. Clin Cancer Res. 2002; 8:2505-2511. [PubMed: 12171876]

13. Brennan, MF.; Alektiar, KM.; Maki, RG. Soft tissue sarcoma. In: DeVita, VT.; Hellman, S.; Rosenberg, SA., editors. Cancer: Principles and practice of oncology. Lippincott Williams \& Williams; 2001. p. 1841-1891.

14. Moertel CG. Treatment of carcinoid tumor and the malignant carcinoid syndrome. J Clin Oncol. 1983; 1:787-40. [PubMed: 6366132]

15. Su Y, Amiri KI, Horton LW, Yu Y, Ayers GD, Koehler E, et al. A phase I trial of bortezomib with temozolomide in patients with advanced melanoma: toxicities, antitumor effects, and modulation of therapeutic targets. Clin Cancer Res. 2010; 16:348-357. [PubMed: 20028756]

16. Hodi FS, O'Day SJ, McDermott DF, Weber RW, Sosman JA, Haanen JB, et al. Improved survival with ipilimumab in patients with metastatic melanoma. N Engl J Med. 2010; 363:711-723. [PubMed: 20525992]

17. Prieto PA, Yang JC, Sherry RM, Hughes MS, Kammula US, White DE, Levy CL, Rosenberg SA, Phan GQ. CTLA-4 blockade with ipilimumab: long-term follow-up of 177 patients with metastatic melanoma. Clin Cancer Res. 2012; 18:2039-2047. [PubMed: 22271879]

18. Grossmann A, Grossmann K, Wallander M. Molecular testing in malignant melanoma. Diagn Cytopathol. 2012; 40:503-510. [PubMed: 22619125]

19. Bauer S, Parry JA, Mühlenberg T, Brown MF, Seneviratne D, Chatterjee P, Chin A, Rubin BP, Kuan SF, Fletcher JA, Duensing S, Duensing A. Proapoptotic activity of bortezomib in gastrointestinal stromal tumor cells. Cancer Res. 2010; 70:150-159. [PubMed: 20028860]

20. Guo J, Si L, Kong Y, Flaherty KT, Xu X, Zhu Y, Corless CL, Li L, Li H, Sheng X, Cui C, Chi Z, Li S, Han M, Mao L, Lin X, Du N, Zhang X, Li J, Wang B, Qin S. Phase II, open-label, single-arm trial of imatinib mesylate in patients with metastatic melanoma harboring c-Kit mutation or amplification. J Clin Oncol. 2011; 29:2904-2909. [PubMed: 21690468]

21. Enzler T, Sano Y, Choo MK, Cottam HB, Karin M, Tsao H, Park JM. Cell-selective inhibition of NF-KB signaling improves therapeutic index in a melanoma chemotherapy model. Cancer Dis. 2011; 1:496-507.

22. Li C, Chen S, Yue P, Deng X, Lonial S, Khuri FR, Sun SY. Proteasome inhibitor PS-341 (bortezomib) induces calpain-dependent IkappaB(alpha) degradation. J Biol Chem. 2010; 285:16096-16104. [PubMed: 20335171] 


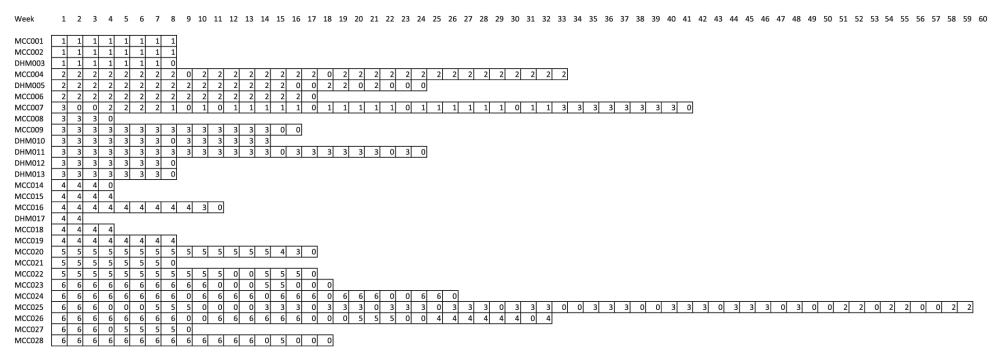

Fig. 1.

Individual patient patterns of dose omission and reduction throughout the course of treatment. Numbers indicate the dose level administered for the corresponding week. " 0 " indicates dose omission 


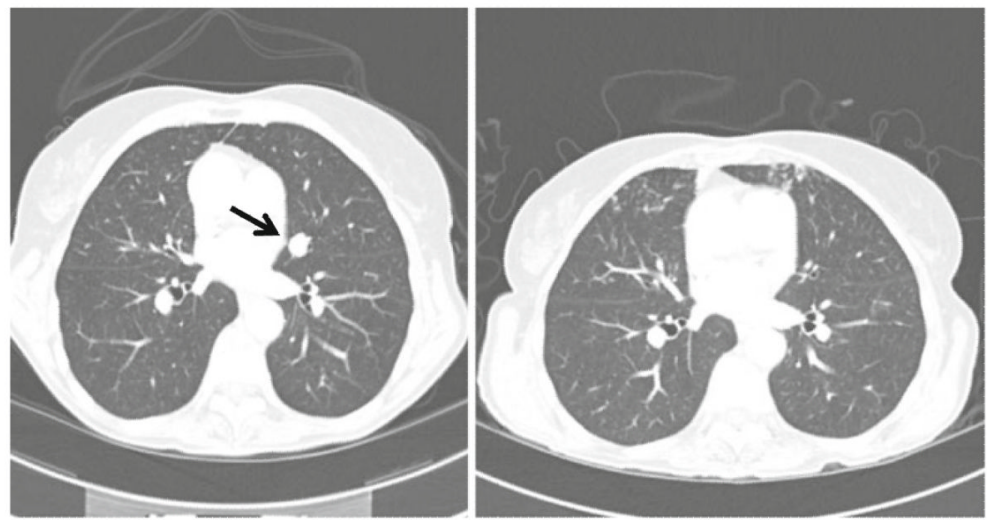

Fig. 2.

Complete response to bortezomib-dacarbazine in a patient with a single pulmonary melanoma metastasis (left, baseline; right, following 5 months of treatment). Serial images show that all remaining structures in the area of interest are vessels 
Table 1

Dose levels, patients enrolled, patients experiencing DLT, nature of DLT

\begin{tabular}{lllll}
\hline Dose level & $\begin{array}{l}\text { Bortezomib } \\
\text { dose }\left(\mathbf{m g} / \mathbf{m}^{2}\right)\end{array}$ & $\begin{array}{l}\text { Dacarbazine } \\
\text { dose }\left(\mathbf{m g} / \mathbf{m}^{2}\right)\end{array}$ & $\begin{array}{l}\text { Patients enrolled/Patients } \\
\text { experiencing DLT }\end{array}$ & $\begin{array}{l}\text { Nature } \\
\text { of DLT }\end{array}$ \\
\hline 1 & 1.0 & 250 & $3 / 0$ & Emesis \\
2 & 1.3 & 250 & $3 / 0$ & \\
3 & 1.6 & 250 & $7 / 1^{a}$ & \\
4 & 1.6 & 330 & $6 / 0^{b}$ & \\
5 & 1.6 & 440 & $3 / 0$ & \\
6 & 1.6 & 580 & $6 / 0$ & \\
\hline
\end{tabular}

\footnotetext{
${ }^{a}$ One patient not evaluable for DLT due to early treatment termination due to progression of disease

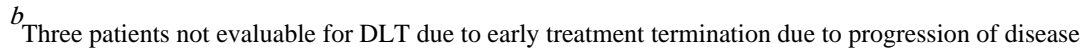


Table 2

Patient characteristics $(n=28)$

\begin{tabular}{|c|c|}
\hline Characteristic & No. of patients \\
\hline \multicolumn{2}{|l|}{ Age } \\
\hline Median & 55 \\
\hline Range & $23-77$ \\
\hline \multicolumn{2}{|l|}{ Gender } \\
\hline Female & 12 \\
\hline Male & 16 \\
\hline \multicolumn{2}{|l|}{ Race/Ethnicity } \\
\hline African-American & 3 \\
\hline Caucasian & 24 \\
\hline \multicolumn{2}{|l|}{ Performance status } \\
\hline 0 & 17 \\
\hline 1 & 11 \\
\hline \multicolumn{2}{|c|}{$\begin{array}{l}\text { Tumor Type (Number of patients with prior } \\
\text { systemic therapies for metastatic disease) }\end{array}$} \\
\hline Melanoma & $15\left(1^{a}\right)$ \\
\hline Soft tissue sarcoma & $12\left(7^{b}\right)$ \\
\hline Carcinoid & $1\left(1^{b}\right)$ \\
\hline Interleukin-2 & \\
\hline
\end{tabular}


Table 3

Number of patients experiencing grade $\geq 2$ toxicity at any time during treatment $(n=28)$

\begin{tabular}{|c|c|c|c|}
\hline Parameter & Grade 2 & Grade 3 & Grade 4 \\
\hline Abdominal pain & 2 & & \\
\hline Alkaline phosphatase elevation & 1 & & \\
\hline Anemia & 3 & & \\
\hline Anorexia & 1 & & \\
\hline AST/SGOT & 1 & & \\
\hline Atrial fibrillation & & 1 & \\
\hline Back pain & 1 & & \\
\hline Constipation & 1 & & \\
\hline Cough & 1 & & \\
\hline Depression & 1 & & \\
\hline Diarrhea & 6 & 1 & \\
\hline Dyspepsia & 1 & & \\
\hline Dyspnea & & & 1 \\
\hline Emesis & 3 & 2 & \\
\hline Fatigue & 8 & 2 & \\
\hline Hyperglycemia & 1 & & \\
\hline Hypoalbuminemia & 1 & & \\
\hline Hypocalcemia & 1 & & \\
\hline Hypokalemia & & 1 & \\
\hline Hyponatremia & & 1 & 1 \\
\hline Hypoxia & & 1 & \\
\hline Trush & 1 & & \\
\hline Upper airway infection & 1 & & \\
\hline URI & 1 & & \\
\hline Insomnia & 1 & & \\
\hline Leukocytes (total WBC) & 3 & 1 & \\
\hline Lymphopenia & 7 & 3 & \\
\hline Muscle weakness & & 1 & \\
\hline Myalgias & 1 & & \\
\hline Nausea & 3 & & \\
\hline Neuropathy & 1 & 1 & \\
\hline Neutropenia & 1 & 1 & \\
\hline Abdominal pain & 1 & & \\
\hline Platelets & 2 & 1 & \\
\hline Pulmonary/Respiratory/COPD & 1 & & \\
\hline Rash/Desquamation & 1 & & \\
\hline Weight loss & 1 & & \\
\hline
\end{tabular}

Invest New Drugs. Author manuscript; available in PMC 2013 December 01. 
Table 4

Treatment response

\begin{tabular}{llll}
\hline & $\begin{array}{l}\text { Melanoma } \\
(\boldsymbol{n}=\mathbf{1 5})\end{array}$ & $\begin{array}{l}\text { Soft tissue } \\
\text { sarcoma }(\boldsymbol{n}=12)\end{array}$ & $\begin{array}{l}\text { Carcinoid } \\
(\boldsymbol{n}=\mathbf{1})\end{array}$ \\
\hline $\begin{array}{l}\text { Complete response } \\
(\mathrm{CR})\end{array}$ & 1 & 0 & 0 \\
$\begin{array}{l}\text { Partial response (PR) } \\
\text { Total CR + PR (\%) }\end{array}$ & 1 & 1 & 0 \\
\hline
\end{tabular}

Invest New Drugs. Author manuscript; available in PMC 2013 December 01. 